\title{
The pleasure of excellence-led growth and the pain of enforcing publishing ethics: the experience of PMBP
}

\author{
N. Raghuram ${ }^{1}$
}

Published online: 1 February 2017

(c) Prof. H.S. Srivastava Foundation for Science and Society 2017

Happy New Year. PMBP has crossed many important milestones in the year 2016, which are far more significant than any others it has crossed over the two decades of its existence. The first and the most important of them is its dramatic entry into the databases of Thomson Reuters with an impact factor of 1.351, the highest entry level score for any journal of Indian origin. This is also by far the highest score achieved by any plant journal of Indian origin, even though this is still a very modest score by global standards, even in plant science. For over a decade, PMBP has already been included in all the major indexing and abstracting services including Scopus, with an impact factor of 1.45 and SJR of 0.479. According to Scopus, PMBP is currently ahead of 270 of the 382 plant science journals globally, between the top one-third and the 1st quartile. However, there is a long way to go.

The second milestone is that PMBP obtained over a thousand citations on Google Scholar in the year 2016 (Fig. 1). Indeed, the journal grew fivefold in citation impact (Fig. 2) and 3.3-fold in SJR over the last 8 years, since we relaunched PMBP as a quarterly with online submission, tracking and full text electronic version with the support of Springer. A citation profile of PMBP has been created on Google Scholar for those who wish to keep track of the journal's growth in real time (http://scholar.google.co.in/ citations?user=hLrG91UAAAAJ\&hl=en). Similarly, Scopus provides regular updates of the performance statistics of journals, including PMBP (http://scimagojr.com/journal search.php?q=16532\&tip=sid \&clean=0).

N. Raghuram

pmbp@ipu.ac.in; raghuram@ipu.ac.in

1 School of Biotechnology, Guru Gobind Singh Indraprastha University, Dwarka, New Delhi 110078, India
The third milestone is that the total submissions to PMBP nearly doubled in 2016, whereas the previous doubling took over 6 years (2009-2015). The previous growth allowed us to steadily increase the number of published articles even while maintaining the rejection rate at $70 \%$. The rapid growth of submissions in the last year strengthens our plans to increase the frequency of publication from quarterly to bimonthly next year without compromising on quality.

The fourth milestone is that for the first time in 2016, the $\%$ submissions from abroad have touched $51 \%$, pushing Indian submissions to a minority and making it a truly international journal. Even though PMBP always had $15-20 \%$ of papers from abroad, this percentage has steadily increased in the last 5 years, crossing the halfway mark in 2016 (Fig. 3).

For the editorial team of PMBP, this is a vindication of our vision and road map spelt out over a decade ago (Editorial 2005), based on our bibliometric analysis of the global plant science literature through the previous decade (Raghuram 2004). We also thank our 500+ reviewers from over 45 countries whose rigorous evaluation has not only helped the journal grow in quality over the years, but also prevented many cases of misconduct from reaching the publication stage. Our annual acknowledgement for the reviewers of 2016 is published elsewhere in this issue.

However, even the most rigorous editors and peer reviewers can only reduce the misconduct but cannot eliminate it altogether. The incorporation of iThenticate scanning of every incoming manuscript for text similarities in the Editorial Manager system has been of tremendous help in timely detection of text plagiarism in the last few years. Such papers were promptly rejected and in the worst cases, even the employers of authors have been informed. We hope that their employers have done the needful to 


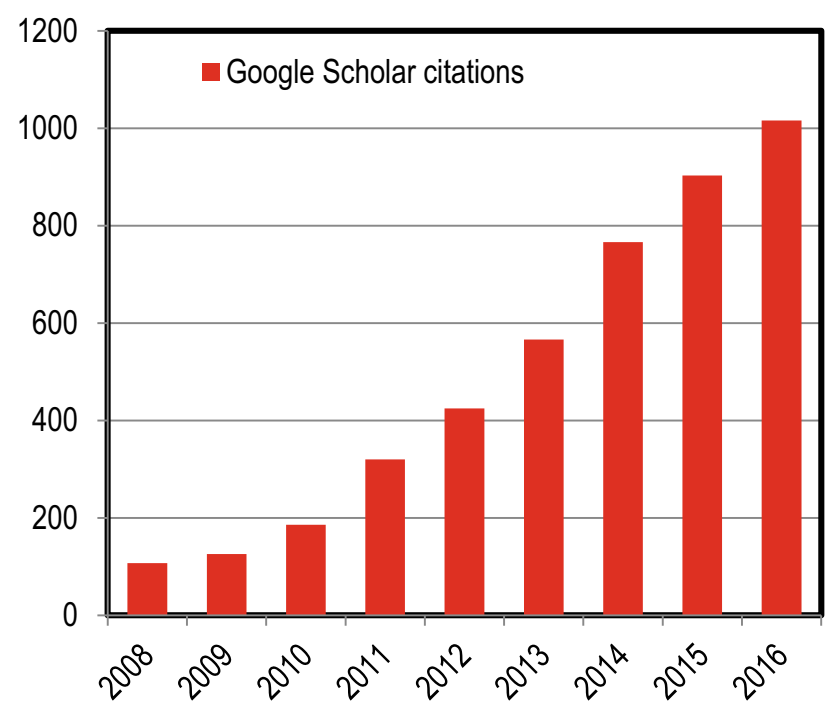

Fig. 1 Annual growth in citations to PMBP

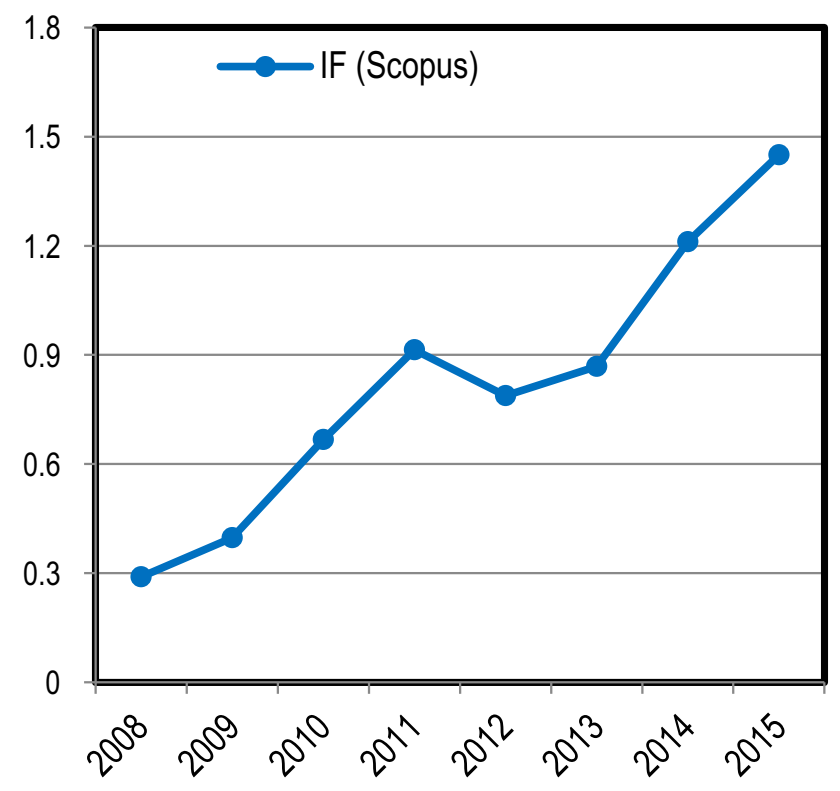

Fig. 2 Annual growth in impact (Scopus)

deter misconduct, though PMBP never received any confirmation to this effect in any such case so far. Unfortunately, this is also the experience of the Society for Scientific Values (SSV), the first of its kind in the world, a registered society of scientists committed to investigating misconduct and generating public awareness (www.scien tificvalues.org). Unlike the scientific community in many Western countries that did not mount an organized response to misconduct till their governments intervened and established offices of research integrity in the 1990s, Indian scientists voluntarily founded SSV way back in 1986. Even though its campaigns created tremendous peer pressure, it often required media intervention to elicit any

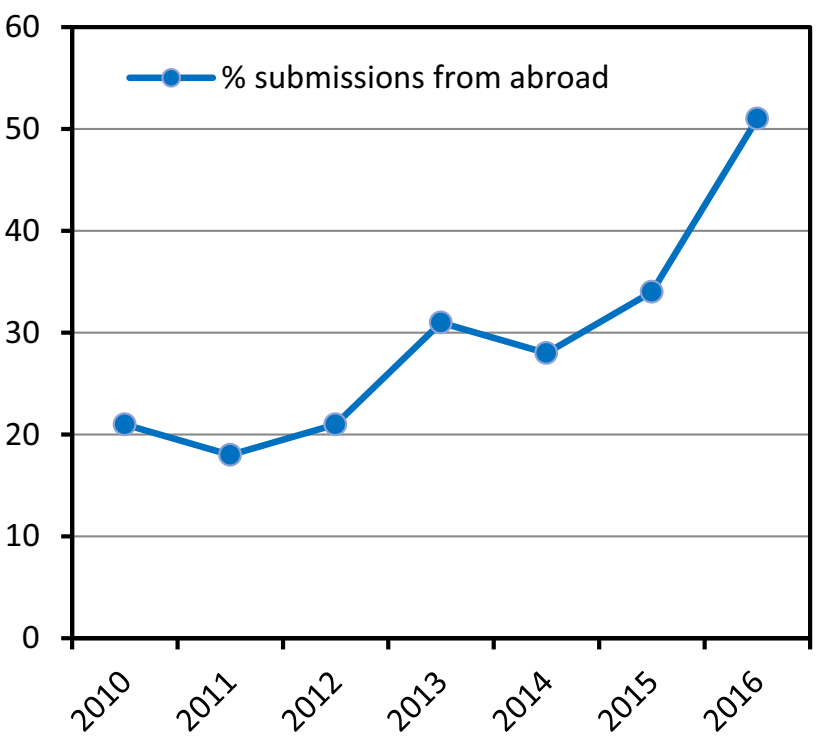

Fig. 3 Growth in \% submissions from abroad

action from employers, national academies and the government (Raghuram 2005).

Notwithstanding our best efforts to maintain high standards of publishing ethics as per COPE guidelines (http:// publicationethics.org), few instances of data duplication/manipulation have escaped the notice of editors and peer reviewers. Whenever such papers published in PMBP were brought to our attention, they were enquired into and retracted if they were beyond correction (Das 2016; Dasgupta et al. 2016; Dwivedi and Kumar 2016; Mukhtar et al. 2016; Pradhan et al. 2013; Rawat et al. 2016; Rizvi et al. 2015; Sanju et al. 2015). In 2016, several such articles have been reported at pubpeer, a website for "post-publication peer review" (http://pubpeer.com). Editorial investigations that followed led to five retractions in 2016 and some more may follow in the near future, if found necessary. Sometimes such cases are impossible to detect prior to publication, as in the case of an author who rapidly submitted different versions of the same work to PMBP and several other journals in quick succession, and was only caught after publication.

Fortunately, cases that warrant retractions form a small fraction of the total number of manuscripts published in PMBP, and almost negligible fraction of all the manuscripts submitted to PMBP, as most of the dubious manuscripts are detected and rejected prior to publication. A cursory glance at the blog, Retraction Watch, will show that no journal, how big its impact factor or reputation, is totally free from such cases (http://retractionwatch.com). Yet, enquiring into allegations of misconduct in published papers can slow down the journal, as editors have to give a reasonable opportunity to the accused to defend their position before deciding whether the published article is amenable to correction or retraction is the only solution. 
Our investigations so far taught us that data recycling and self-plagiarism by authors seeking to multiply their publications constitute the most prevalent form of misconduct, as compared to the more serious forms such as falsification, fabrication or stealing data from others. This allowed us to set up editorial prescreening of submitted manuscripts for data duplication/manipulation prior to peer review, and several articles have already been rejected in the last few months. However, as the 3rd quarter of 2016 witnessed an unprecedented threefold growth in incoming submissions from 55 to 164 , the editorial backlog is refusing to die down despite employing a full time assistant editor for prescreening. We request the authors to cope with the resultant delays in the time taken from submission to decision.

In another measure to deter misconduct, decision letters from PMBP now often include a statement asking the authors to "ensure that your manuscript has no text/data similarities with any published content (even if your own), except in materials, methods and references. PMBP is seriously committed to the novelty and reliability of the published scientific record and holds the authors responsible for the authenticity of their data. Some articles have been retracted after publication for this reason and the employers of the authors have been informed, as per PMBP's ethics policy".

The above statement and the retractions so far, as well as this editorial itself, are a strong indication of the uncompromising commitment of PMBP to publishing ethics. Interestingly, there are a large number of predatory online journals that publish anything submitted for a fee without prior scrutiny or peer review, under the garb of "postpublication peer review". Such journals make a mockery of the very idea of post publication peer review espoused by Pubpeer and others. After all, perfection in scientific publishing is a utopia that is a highly desirable goal but it cannot be easily achieved without the cooperation of all concerned.

\section{References}

Das DK (2016) Retracted article: expression of a bacterial chitinase (ChiB) gene enhances resistance against $E$. polygoni induced powdery mildew disease in the transgenic Black gram (Vigna mungo L.) (cv. T9). Physiol Mol Biol Plants 22:427

Dasgupta N, Biswas P, Kumar R, Kumar N, Bera B, Das S (2016) Retraction note to: antioxidants and ROS scavenging ability in ten Darjeeling tea clones may serve as markers for selection of potentially adapted clones against abiotic stress. Physiol Mol Biol Plants 22:287

Dwivedi SK, Kumar S (2016) Retracted article: effect of paclobutrazol on photosynthesis and expression of pyrroline-5-carboxylatesynthase in contrasting wheat genotypes under water deficit stress condition. Physiol Mol Biol Plants 22:425

Editorial (2005) Physiol Mol Biol Plants 11:1

Mukhtar S, Ahmad N, Khan MI, Anis M, Aref IM (2016) Retraction note to: influencing micropropagation in Clitoria ternatea $\mathrm{L}$. through the manipulation of TDZ levels and use of different explant types. Physiol Mol Biol Plants 22:289

Pradhan C, Das AB, Chand PK (2013) Retracted article: agrobacterium tumefaciens-mediated transformation and efficient regeneration of a timber yielding plant Dalbergia sissoo Roxb. Physiol Mol Biol Plants 19:611

Raghuram N (2004) Indian publishing. Enduring the boom. Trends Plant Sci 9:9-12

Raghuram N (2005) Research integrity and scientific values: a comparison of American and Indian models. Ethics Sci Res Dev Manag News Views 3:8-13

Rawat JM, Rawat B, Mishra S, Bhandari A, Agnihotri RK, Chandra A (2016) Retracted article: influence of Agrobacterium rhizogenes strains, acitosyringone, inoculum size and temperature on production of active ingredients from Picrorhiza kurrooa. Physiol Mol Biol Plants 22:423

Rizvi MZ, Kukreja AK, Bisht NS (2015) Retraction note to: plant regeneration in Chlorophytum borivilianum Sant. et Fernand. from embryogenic callus and cell suspension culture and assessment of genetic fidelity of plants derived through somatic embryogenesis. Physiol Mol Biol Plants 21:617

Sanju S, Thakur A, Siddappa S, Sreevathsa R, Srivastava N, Shukla P, Singh BP (2015) Retraction note to: pathogen virulence of Phytophthora infestans-from gene to functional genomics. Physiol Mol Biol Plants 21:167 